\title{
Quantitative variation in adult size and fecundity of the cotton stainer bug Dysdercus fasciatus
}

\author{
F. K. KASULE \\ Department of Zoology, University of Dar es Salaam, P.O. Box 35064, Dar es Salaam, Tanzania
}

\begin{abstract}
Genetic variation in adult size and fecundity was studied in the cotton stainer bug Dysdercus fasciatus in the laboratory using a split-family, two-environment, half-sib, full-sib design. Groups of siblings were grown in either a benign or a stressful moisture environment. Sib analysis in each environment revealed additive genetic variance for adult size and fecundity only in the benign environment. Heritability estimates were zero for adult size and low for fecundity when averaged over the two environments. A substantial component of the phenotypic variance in adult size and fecundity was due to genotype-by-environment interaction. This result indicates that different genotypes would be favoured in different conditions if the selection occurred in a heterogeneous moisture environment.
\end{abstract}

Keywords: adult size, Dysdercus fasciatus, fecundity.

\section{Introduction}

Size is a critical facet of life-history evolution (Stearns, 1984). In particular, large females are often more fecund (Bluewiess et al., 1978; Llewellyn \& Brown, 1985; Willows, 1987) and produce larger offspring (Crump, 1981; Derr et al., 1981; Griffiths, 1985; Holloway et al., 1987; Willows, 1987) than small ones; and large males usually have enhanced mating success (Trivers, 1976; Cox \& Le Boeuf, 1977; Ward, 1983). However, while there have been many studies of the relationship between size and other fitness characters such as fecundity, the heritability of size variation is known only in a few species (e.g. Hegmann \& Dingle, 1982 ), and so the evolutionary result of an increase or decrease in size cannot be assessed.

In this paper, the result of a study to document the extent of genetic variation in adult size and fecundity in two moisture environments in the cotton stainer bug Dysdercus faciatus Sign. is reported. The genetic association of fecundity with adult size in this species is described in another paper (Kasule, 1991). Moisture was used as an environmental variable in the study because it seemed that it may be an important factor contributing to life-history variation in Dysdercus species (Pearson, 1958; Derr, 1980a). These bugs are seed predators of Malvales (Pearson, 1958), and both larvae and adults feed by injecting saliva into the seed and sucking the partially-digested soup. Very dry conditions in the field have been associated with the migration of Dysdercus species from crops where seeds were still plentiful (Whitfield, 1933; Pearson, 1958).

\section{Methods}

\section{Rearing and experimental design}

The $D$. fasciatus used in this experiment were firstgeneration progeny of parents collected copulating in the field. The insects were from kapok (Ceiba pentan$d r a$ L.) in the environs of the University of Dar es Salaam campus. Over 100 females were collected.

Upon collection from the field, each female was allowed to lay a clutch of eggs in a clear plastic cage ( $60 \mathrm{~mm}$ diam. $\times 40 \mathrm{~mm}$ ) with a snap-on gauze lid. The cage contained kapok seeds and water delivered via a standard pad of tissue paper in the base. The eggs laid by each female were hatched separately. Within not more than $24 \mathrm{~h}$ after moulting, 15-s instar larvae of the progeny of each female were aspirated with a pooter and placed into a cage containing two sticks (perches), kapok seeds and a moist pad of tissue paper in the base (first instar larvae are non-feeding). Water was added to the tissue paper daily, and the seeds were changed every 2 days until adults emerged. One virgin male or female was collected at random from the progeny of 
each field-collected female and used for the experimental matings.

The experiment involved the growth of groups of sibling larvae in either benign or stressful moisture environments. Single-pair matings were performed in cages in a nested half-sib mating design: two unrelated virgin females (dams) were mated to a single male (sire) to generate both full-sib and half-sib families (Robertson, 1959; Falconer, 1981). Paternal half-sib families were used to derive estimates of the additive genetic component of phenotypic variance, while the variance among offspring of females within males consists of a combination of dominance, epistatic and maternaleffect (common environment) variances (Falconer, 1981). From each dam, second instar larvae not more than $24 \mathrm{~h}$ old were assigned at random to two moisture environments as follows. Larvae were placed 15 per cage in each of four cages. Larvae in two cages were given water ad libitum (pad of tissue paper in the base of the cage always moist = benign environment), and larvae in the other two cages were given $1.5 \mathrm{ml}$ of water every 2 days (pad of tissue paper always dry by the day water is added to it $=$ stressful environment). In both cases larvae were offered abundant seeds, and these were changed every 2 days until adults emerged. Upon eclosion, four females were taken at random from each cage and weighed singly to $0.1 \mathrm{mg}$ within $24 \mathrm{~h}$ of adult emergence. Each female was then confined with a male in a cage containing kapok seeds, and was returned to the environment in which she had grown to lay eggs. The number of eggs laid in the first clutch by each of these females was scored and used as an index of fecundity.

All rearings were conducted in an environmental chamber at $28^{\circ} \mathrm{C} 12 \mathrm{~h}$ light and $26^{\circ} \mathrm{C} 12 \mathrm{~h}$ dark.

\section{Analysis}

The original intention was to assay four females from each replicate in each environment, but pre-reproductive mortality reduced the number assayed for each dam to three or two females per replicate. Because of the limitation of computing facilities, a balanced design was necessary for the analysis of variance (ANOVA). To obtain a balanced data set, dams that did not have three surviving progeny per replicate in each environment were not included in the analysis, and progeny in excess of three per replicate were randomly removed. A total of 26 half-sib families containing 624 females (312 females in each moisture environment) were employed for adult-size and fecundity measurements.

The data were tested for effects of moisture $(M)$, sire $(s)$, dam $(d)$ and interactions of sire-by-moisture $(M s)$ and dam-by-moisture $(M d)$ by a partially-nested two- way ANOVA. Data were transformed to $\log _{10}$ to guard against violation of the assumptions of ANOVA (Sokal \& Rohlf, 1981) and the estimation of scale-dependent genotype-by-environment interaction (Bulmer, 1981; Falconer, 1981).

The linear model for this experiment is:

$$
Y_{i j k l m}=\mu+M_{i}+s_{j}+d_{j k}+R_{j k l}+(M s)_{i j}+(M d)_{i j k}+e_{i j k l m} \cdot(1)
$$

This is a mixed model (Sokal \& Rohlf, 1981) in which $Y_{i j k l m}$ is the measurement on the $m$ th female in the $l$ th replicate $(R)$ from the $i$ th moisture environment (a fixed treatment effect) produced by the $k$ th dam nested in the $j$ th sire. Effects due to sire, dam and residual $(e)$ were assumed to be random effects with zero means and variances $V_{s}, V_{d}$, and $V_{r}$, respectively.

The genetic model for the variance of character $Y$, assuming absence of a significant amount of epistatic variation (Falconer, 1981) is:

$$
V_{Y}=V_{P}=V_{A}+V_{D}+V_{C}+V_{I(A)}+V_{I(D)}+V_{I(C)}+V_{e}
$$

where $V_{P}=$ phenotypic variance, $V_{A}=$ additive genetic variance, $V_{D}=$ dominance genetic variance, $V_{C}=$ common environmental variance, $V_{I(A)}=$ additive genetic variance component of the genotype-byenvironment interaction, $V_{I(D)}=$ dominance genetic variance component of the genotype-by-environment interaction, $V_{I(C)}=$ common environmental variance component of the genotype-by-environment interaction and $V_{e}=$ residual variance unique to the individual bug.

Observational variances from sires, dams and progenies $\left(V_{r}\right)$ were used to obtain estimates of the various variance components. Their genetic expectations, assuming absence of epistatis (Falconer, 1981), are:

$V_{s}=\frac{1}{4} V_{A}$,

$V_{d}=\frac{1}{4} V_{A}+\frac{1}{4} V_{D}+V_{C}$,

$V_{r}=\frac{1}{2} V_{A}+\frac{3}{4} V_{D}+V_{e}$.

Note in (4) that a significant dam effect might result from genetic variation in a character that is additive or non-additive plus common environmental (maternal) effects. Thus, the phenotypic variance can be divided into: (1) the additive genetic variance, $V_{A}=4 V_{s},(2)$ a non-additive genetic plus maternal-effect variance component, $V_{N A+M}=4\left(V_{d}-V_{s}\right)=V_{D}+V_{C},(3)$ an additive variance component of genotype-by-environment interaction, $V_{I(A)}=4 V_{M s}$, (4) a non-additive genetic plus maternal-effect variance component of genotype-byenvironment interaction, $V_{I(N A+M)}=4\left(V_{M d}-V_{M S}\right)=$ $V_{I(D)}+4 V_{I(C)}$, and (5) a residual environmental variance component, $V_{e}=V_{r}-\left(3 V_{d}-V_{s}\right)-\left(3 V_{M d}-V_{M s}\right)$. A significant effect of female parent in the absence of a 
male-parent effect indicates that dominance or maternal effects exert a major influence on the variation of a character.

To assess the influence of growth conditions on the variance of a character, data from each environment were analysed separately using a hierarchical model II ANOVA (Sokal \& Rohlf, 1981):

$Y_{i j k l}=\mu+s_{i}+d_{i j}+R_{i j k}+e_{i j k l}$

where the symbols are as defined before.

The analysis-of-variance method may occasionally result in the estimation of negative variance components (Searle, 1971, p. 406). Negative estimated values of observational variance components were used to obtain estimates of other observational variance components and causal variance components. Causal variance components with negative estimated values are reported as zero.

\section{Calculation of heritabilities}

Narrow-sense heritabilities, which represent the proportion of phenotypic variance accessible to selection, were calculated as $4 V_{s} / V_{P}$ (Falconer, 1981). Standard errors were also calculated according to the formula in Falconer (1981, p. 169).

\section{Results}

Table 1 gives the means of adult size and fecundity for siblings grown in benign versus stressful environments. Consider results from a two-way ANOVA first. Table 2 gives the results of the analysis of variance of the two characters. Table 3 gives the subdivision of phenotypic variance into its component parts for log adult size and $\log$ fecundity.

ANOVA indicated a significant effect of moisture on adult size and fecundity (Tables 1 and 2). There were no significant effects of male and female parents on either of the two characters studied (Table 2). Significant interaction was found between full-sib families (dams) and moisture for both adult size and fecundity (Table 2). The significant dam-by-moisture term indicates genotype-by-environment interaction for these characters, and suggests that a family's performance in one environment is not predictive of performance in the other.

Examination of variance components (Table 3) shows that there was no additive genetic component to phenotypic variability in $\log$ adult size. There was, however, a moderate ( 31 per cent) non-additive genetic or maternal contribution to the phenotypic variance. The additive and non-additive interactions together comprised 49 per cent of the phenotypic variance. The additive genetic component was the larger of the two components of genotype-by-environment interaction variance (Table 3). The residual environmental component of variance, expressed as a proportion of the total phenotypic variance, was 0.2 .

Log fecundity was moderately heritable in these bugs. Twenty-four per cent of the total phenotypic variance was of an additive genetic nature (Table 3 ). This heritability estimate represents the degree of genetic determination when averaged over the two environments. The non-additive genetic plus maternaleffect component of variance was 0.12 . The additive genetic interaction comprised 14 per cent of the total phenotypic variance, and the remaining half of the total phenotypic variance was due to non-additive genetic or maternal-effect interaction (Table 3). Residual environmental effects were not important in fecundity variability in this sample of Dysdercus fasciatus.

Table 4 gives estimates of the underlying components of phenotypic variability in log adult size and log fecundity in benign versus stressful environments. Log adult size was moderately heritable in a benign environment, but not in a stressful one (Table 4). Nonadditive genetic or maternal effects in benign and stressful environments were 0.21 and 0.91 , respectively. The residual environmental contribution to the phenotypic variance was 0.55 in a benign environment and zero in a stressful environment.

Log fecundity was highly heritable in a benign environment (Table 4). By contrast, the heritability of $\log$ fecundity in a stressful environment is not significantly greater than zero, given the large standard error (Table 4). The non-additive genetic plus maternaleffect component of variance was zero in a benign environment and 0.92 in a stressful environment. Residual environmental effects in benign and stressful environments were 0.24 and zero, respectively.

In summary, these results (Table 4) indicate that the relative magnitudes of the components of phenotypic variance in adult size and fecundity differed between the two environments. Additive genetic and residual environmental effects were important in a benign environment, whereas a remarkably large component of non-additive genetic or maternal effects conditioned the phenotypic expressions of adult size and fecundity in a stressful environment (Table 4).

Table 1 Means and standard errors for adult size (mg) and fecundity (eggs in first clutch) scored on Dysdercus fasciatus females grown in benign and stressful environments

\begin{tabular}{lcc}
\hline & Benign & Stressful \\
\hline Adult size & $131.8 \pm 1.01$ & $106.8 \pm 1.01$ \\
Fecundity & $120 \pm 1$ & $86 \pm 1$ \\
\hline
\end{tabular}


Table 2 Analysis of variance for (a) $\log$ adult size and $\langle\mathrm{b}\rangle \log$ fecundity of Dysdercus fasciatus grown in benign versus stressful environments

\begin{tabular}{lrlllrl}
\hline Source & d.f. & SS & M & $F$ ratio & \multicolumn{1}{l}{$F$} & $P$ \\
\hline (a) Log adult size & & & & & & \\
$\quad$ Moisture & 1 & 1.302687 & M1 & M1/M7 & 788.07 & $<0.001$ \\
Sire & 25 & 0.144603 & M2 & M2/M3 & 0.98 & $<0.50$ \\
Dam & 26 & 0.153588 & M3 & M3/M5 & 1.54 & $<0.25$ \\
Sire $\times$ moisture & 25 & 0.143876 & M4 & M4/M5 & 1.50 & $<0.25$ \\
Dam $\times$ moisture & 26 & 0.099533 & M5 & M5/M6 & 1.75 & $<0.25$ \\
Replicate & 104 & 0.227961 & M6 & M6/M7 & 1.33 & $<0.01$ \\
Residual & 416 & 0.687533 & M7 & & & \\
Total & 623 & 2.759781 & & & & \\
(b) Log fecundity & & & & & & \\
Moisture & 1 & 3.345036 & M1 & M1/M7 & 939.92 & $<0.001$ \\
Sire & 25 & 0.715702 & M2 & M2/M3 & 1.49 & $<0.25$ \\
Dam & 26 & 0.498337 & M3 & M3/M5 & 1.6 & $<0.25$ \\
Sire $\times$ moisture & 25 & 0.368382 & M4 & M4/M5 & 1.23 & $<0.5$ \\
Dam $\times$ moisture & 26 & 0.310588 & M5 & M5/M6 & 2.18 & $<0.005$ \\
Replicate & 104 & 0.570419 & M6 & M6/M7 & 1.54 & $<0.001$ \\
Residual & 416 & 1.480491 & M7 & & & \\
$\quad$ Total & 623 & 7.288955 & & & & \\
\hline
\end{tabular}

Table 3 Partition of phenotypic variance components for (a) log adult size and (b) log fecundity of Dysdercus fasciatus grown in benign versus stressful environments. The additive component of the variance $\left(V_{A}\right)$ is the degree of genetic determination averaged over the two moisture environments

\begin{tabular}{ll}
\hline $\begin{array}{l}\text { Observational variance } \\
\text { components }\left(\times 10^{-3}\right)\end{array}$ & $\begin{array}{l}\text { Causal variance } \\
\text { components }\end{array}$ \\
\hline
\end{tabular}

\begin{tabular}{llll}
\hline (a) Log adult size & & & \\
$V_{s}$ & 0.005 & $V_{A}$ & 0.0 \\
$V_{d}$ & 0.173 & $V_{N A+M}$ & 0.31 \\
$V_{M s}$ & 0.161 & $V_{I(A)}$ & 0.29 \\
$V_{M d}$ & 0.273 & $V_{(N A+M)}$ & 0.20 \\
$V_{r}$ & 1.653 & $V_{e}$ & 0.20 \\
$V_{p}$ & 2.255 & & \\
(b) Log fecundity & & & \\
$V_{s}$ & 0.394 & $V_{A}$ & $0.24 \pm 0.11$ \\
$V_{d}$ & 0.602 & $V_{N A+M}$ & 0.12 \\
$V_{M s}$ & 0.232 & $V_{I(A)}$ & 0.14 \\
$V_{M d}$ & 1.077 & $V_{I(N A+M)}$ & 0.50 \\
$V_{r}$ & 3.559 & $V_{e}$ & 0.00 \\
$V_{p}$ & 5.864 & & \\
\hline
\end{tabular}

\section{Discussion}

Heritability estimates are uncomfortably imprecise when based on small sample sizes (Robertson, 1959; Falconer, 1981). The results presented here are based on 26 half-sib families, each of which had only two females per male and 12 individuals in each environ-
Table 4 A comparison of the components of phenotypic variance for log adult size and log fecundity of Dysdercus fasciatus grown in (a) benign versus (b) stressful environments. The additive components of the variance $\left(V_{A}\right)$ is the narrow-sense heritability

\begin{tabular}{lll}
\hline & Adult size & Fecundity \\
\hline $\begin{array}{ll}\text { (a) Benign } \\
V_{A}\end{array}$ & $0.245 \pm 0.156$ & $0.76 \pm 0.279$ \\
$V_{N A+M}$ & 0.207 & 0.0 \\
$V_{e}$ & 0.548 & 0.24 \\
(b) Stressful & & \\
$V_{A}$ & $0.094 \pm 0.098$ & $0.083 \pm 0.095$ \\
$V_{N A+M}$ & 0.906 & 0.917 \\
$V_{e}$ & 0.0 & 0.0 \\
\hline
\end{tabular}

ment. The standard errors induced by small sample sizes suggest caution in interpretation of these results.

Although the degree of genetic determination was zero for adult size and low for fecundity when averaged over the two moisture environments (Table 3), there was a sizeable amount of heritable variation in adult size, and fecundity displayed abundant additive genetic variance in a benign environment (Table 4), subject to sampling error. By contrast, the genetic variation of these characters had different properties in a stressful environment, being entirely ascribable to maternal or non-additive genetic effects (Table 4).

A likely explanation for the large contribution of the 
non-additive genetic plus maternal-effect component to the phenotypic variance of adult size and fecundity in a stressful environment (Table 4) is that maternal effects are somewhat more likely to be manifest in stressful than in benign conditions (Crump, 1984). Large females are more fecund than small ones, and size of offspring is, as generally accepted, affected by maternal size. In addition, a large offspring may fare better than a small one. Therefore, some of the variance among full-sib families in a stressful environment may have stemmed from differences among the dams in their patterns of egg provisioning, the effect of which may persist throughout life. This suggests that maternal effects may provide a potential mechanism for changing characters, which are related to size, through selection on maternal phenotype (Kirkpatrick \& Lande, 1989).

Relatively few similar studies have been published, but their results are generally in accord with this one. McLaren (1976) found that the heritability of several life-history characters in the copepod, Eurytemora herdmani, was low when individuals were grown at temperatures resembling those in their natural environments, but high at other temperatures. Giesel et al. (1982) and Murphy et al. (1983) found large shifts in heritability estimates with changes in environmental temperature for several fitness characters of Drosophila melanogaster and $D$. simulans, respectively. Berven (1988) found that body size in mountain and lowland populations of the frog, Rana sylvatica, exhibited abundant additive genetic variance, but that development time was strongly heritable only in the mountain population.

These studies show that the difference in the components of phenotypic variance in fitness characters between the two environments in the present investigation (Table 4) is not unique to $D$. fasciatus. Other workers have criticized the estimation of genetic parameters in only one set of environmental conditions. Murphy et al. (1983) pointed out that estimation of genetic variation in only one set of environmental conditions may not be useful in providing insight into what may be happening in natural populations which, presumably, experience variable selection pressures. Via (1984) maintained that only studies which address the possibility of genotype-by-environment interactions will produce realistic estimates of genetic variation for organisms in heterogenous environments.

The data in Table 3 show that genotype-byenvironment interactions explained a substantial proportion of the phenotypic variance for adult size and fecundity in $D$. fasciatus. This result is significant in light of the question of how heritable variation is maintained for fitness characters.
A corollary of Fisher's fundamental theorem (Fisher, 1930) is that additive genetic variance for fitness or major components of fitness is expected to be low (Falconer, 1981) because directional selection tends to erode most of the mutant genetic variability. Adult size and fecundity have obvious effects on fitness (Falconer, 1981, p. 308), and so are expected to have low heritabilities. Table 4 shows, however, that these characters, especially fecundity, displayed considerable heritable variation in a benign environment. Other workers have also shown substantial amounts of additive genetic variation in the life-history characters of many species (McLaren, 1976; Derr, 1980b; Rose \& Charlesworth, 1981; Hegmann \& Dingle, 1982; Murphy et al., 1983; Mousseau \& Roff, 1987; Berven, 1988).

A variety of hypotheses have been advanced to account for the presence of genetic variation in lifehistory characters including, (1) mutation-selection balance (Lande, 1975; Turelli, 1984; Keightley \& Hill, 1988), (2) antagonistic pleiotropy between fitness characters (Falconer, 1977; Rose, 1982), and (3) selection varying in direction in space and time (Haldane \& Jayaker, 1963; Hedrick et al., 1976; Ewing, 1979). My data suggest that selection could result in genetic variance if the selection occurred in a heterogenous environment.

The genotype-by-environment interaction variance estimated in adult size and fecundity (Table 3 ) demonstrates genetic variability in the relative performance of individuals in different environments. Similar results have been shown for other organisms. Dobzhansky \& Spassky (1944) and Gupta \& Lewontin (1982) found that genotypes changed rank in viability at different temperatures in Drosophila pseudoobscura. The classic work of Clausen et al. (1948) on the response of plant size to elevation among clones of Achillea indicates significant genotype-by-environment interaction. Parsons (1977) found significant genotype-by-temperature interaction variance in longevity for Drosophila simulans. Giesel et al. (1982) and Murphy et al. (1983) found that genotypes changed positions with changes in temperature in D. melanogaster and D. simulans, respectively. Via (1984) found significant genotype-byenvironment interaction in development time on two host plant species in the fly Liriomyza sativa.

From an evolutionary perspective, these observations suggest that if high-performance genotypes in one environment differ from those in another, we would expect different genotypes to be selected under different conditions in a heterogeneous environment. So, when individuals mix in the random mating pool, any genotypic differences among individuals selected under different conditions are likely to have a large 
effect on the genetic variance in the mating pool, whether or not Fisher's fundamental theorem is in force.

\section{Acknowledgements}

I thank J. Goha for his technical assistance. The manuscript benefited greatly from the comments and suggestions of two anonymous referees.

\section{References}

BERVEN, K. A. 1988. The heritability basis of variation in larval developmental patterns within populations of the wood frog (Rana sylvatica). Evolution, 41, 1088-1097.

BLUEWEISS, L., FOX, H., KUDZMA, V., NAKASHIMA, A. D., PETER, R. AND SAMS, S. 1978. Relationship between body size and some life history parameters. Oecologia, 37, 257-272.

BULMER, M. G. 1981. The Mathematical Theory of Quantitative Genetics, Oxford University Press, Oxford.

CLAUSEN, J., KECK, D. D. AND HIESEY, W. N. 1948. Experimental Studies on the nature of species. III. Environmental responses of climatic races of Achillea. Carnegie Institute of Washington Publication 581.

COX, C. R. AND LE BOEUF, B. J. 1977. Female incitation of male competition: a mechanism of mate selection. Am. Natur., 111, 317-335.

CRUMP, M. L. 1981. Variation in propagule size as a function of environmental uncertainty for tree frogs. Am. Natur., 117, 724-737.

CRUMP, M. L. 1984. Intraclutch egg size variability in Hyla crucifer (Anura: Hylidae). Copeia, 1984, 302-308.

DERR, J. A. 1980a. Coevolution of the life history of a seed feeding insect and its host plants. Ecology, 61, 881-892.

DERR, J. A. 1980 b. The nature of variation in life history characters of Dysdercus maculatus, a colonizing species. Evolution, 34, 584-557.

DERR, J. A., ALDEN, B. AND DINGLE, H. 1981. Insect life histories in relation to migration, body size, and host plant array: a comparative study of Dysdercus. J. Anim. Ecol., 50 , 181-193.

DOBZHANSKY, TH. AND SPASSKY, B. 1944. Genetics of natural populations, XI. Manifestation of genetic variants in Drosophila pseudoobscura in different environments. Genetics, 29, 270-290.

EWING, E. P. 1979. Genetic variation in heterogeneous environment. VII. Temporal and spatial heterogeneity in infinite populations. Am. Natur., 114, 199-212.

FALCONER, D. S. 1977. Why are mice the size they are? In: International Conference on Quantitative Genetics, Pollack, E., Kempthorne, E. and Bailey, E. J. (eds), Iowa State University Press, Ames, pp. 19-21.

FALCONER, D. S. 1981. Introduction to Quantitative Genetics, 2nd edn, Longman, London.

FISHER, R. A. 1930. The Genetical Theory of Natural Selection, Cambridge University Press, London.

GIESEL, J. T., MURPhy, P. A. AND MANLOVE, M. N. 1982. The influence of temperature on genetic interrelationships of life history traits in a population of Drosophila melanogaster. Am. Natur., 119, 464-479.

GRIFfITHS, D. 1985. Phenology and larval - adult size relationships in the ant-lion Macroleon quinquemaculatus. $J$. Anim. Ecol., 54, 573-581.

GUPTA, A. P. AND LEWONTIN, R. C. 1982. A study of reaction norms in natural populations of Drosophila pseudoobscura. Evolution, 36, 934-948.

HALDANE, J. B. S. AND JAYAKAR, S. D. 1963. Polymorphism due to selection of varying direction. J. Genet., 58, 237-242.

HEDRICK, P., GINEVAN, N. E. AND EWING, E. P. 1976. Genetic polymorphism in heterogeneous environments. Ann. Rev. Ecol. Syst., 17, 535-566.

HegmanN, J. P. AND DINGle, H. 1982. Phenotypic and genetic covariance structure in milkweed bug life history traits. In: Evolution and Genetics of Life Histories, Dingle, M. and Hegman, J. P. (eds), Springer-Verlag, New York, pp. $177-185$.

HOLLOWAY, G. J., SMITH, R. H., WRELTON, A. E., KING, P. E., L1 L1 LI AND MENENDEZ, G. T. 1987. Egg size and reproductive strategies in insects infesting stored-products. Funct. Ecol., 1, 229-235.

KASULE, F. K. 1991. Associations of fedundity with adult size in the cotton stainer bug Dysdercus fasciatus. Heredity, 66 , 277-282.

KEIGHTLEY, P. D. AND HILL, w. G. 1988. Quantitative genetic variability by mutation-stabilizing selection in finite populations. Genet. Res., 52, 33-43.

KIRKPATRIC, M. AND LANDE, R. 1989. The evolution of maternal characters. Evolution, 43, 485-503.

LANDE, R. 1975. The maintenance of genetic variability by mutation in a polygenic character with linked loci. Genet. Res., 26, 221-235.

LLEWELLYN, M. AND BROWN, v. K. 1985. A general relationship between adult size and reproductive potential of aphids. $J$. Anim. Ecol., 54, 663-667.

MCLAREN, 1. A. 1976. Inheritance of demographic and production parameters in the marine copepod Eurytemora herdmani. Biol. Bull., 151, 200-213.

MOUSSEAU, T. A. AND ROFF, D. A. 1987 . Natural selection and the heritability of fitness components. Heredity, 59, 181-197.

MURPHY, P. A., GJESEL, J. T. AND MANLOVE, N. N. 1983. Temperature effects on life history variation in Drosophila simulans. Evolution, 37, 1181-1192.

PARSONS, P. A. 1977. Genotype-temperature interaction for longevity in natural populations of Drosophila simulans. Experimental Gerontology, 12, 241-244.

PEARSON, E. O. 1958. The Insect Pests of Cotton in Tropical Africa, Commonwealth Institute of Entomology, London.

ROBERTSON, A. 1959. Experimental design in the evaluation of genetic parameters. Biometrics, 15, 219-226.

ROSE, M. R. 1982. Antagonistic pleiotropy, dominance and genetic variation. Heredity, 48, 63-78.

ROSE, M. R. AND CHARLESWORTH, B. 1981. Genetics of life history in Drosophila melanogaster. I. Sib analysis of adult females. Genetics, 97, 173-180.

SEARLE, S. R. 1971. Linear Models, John Wiley, New York. SOKAL, R. S. AND ROHLF. F. J. 1981. Biometry, 2nd edn, W. H. Freeman, San Francisco. 
STEARNS, s. C. 1984. The effects of size and phylogeny on patterns of covariation in life-history traits of lizards and snakes. Am. Natur., 123, 56-72.

TRIVERS, R. L. 1976. Sexual selection and resource - accruing abilities in Anolis garmani. Evolution, 30, 253-269.

TURELLI, M. 1984. Heritable genetic variation via mutation selection balance: Lerch's zeta meets the abdominal bristle. Theor. Popul. Biol., 25, 138-193.

VIA, S. 1984. The quantitative genetics of polyphagy in an insect herbivore. I. Genotype - environment interaction in larval performance on different host plant species.
Evolution, 38, 881-895.

WARD, P. I. 1983. The effect of size on the mating behaviour of the dug fly, Sepsis cynipsea. Behav. Ecol. Sociobiol., 13, 75-80.

WHITFIELD, D. G. S. 1933. The bionomics and control of Dysdercus (Hemiptera) in the Sudan. Bull. Entomol. Res., 24, 301-313.

WiLlows, R. I. 1987. Intrapopulation variation in the reproductive characteristics of two populations of Ligia oceanica (Crustacea: Oniscidea). J. Anim. Ecol., 56, 331-340. 